\title{
I disturbi del movimento in età pediatrica
}

GiovanniTricomi

UO Neuropsichiatria dell'Infanzia e dell'Adolescenza, AUSL della Romagna, Cesena

\section{Introduzione}

Il movimento è una funzione complessa che si realizza grazie all'attività integrata del sistema nervoso centrale/periferico e del si- stema muscolo-scheletrico (Figura 1). Nel bambino il controllo motorio si sviluppa parallelamente alla maturazione del sistema nervoso e segue un gradiente rostro-caudale

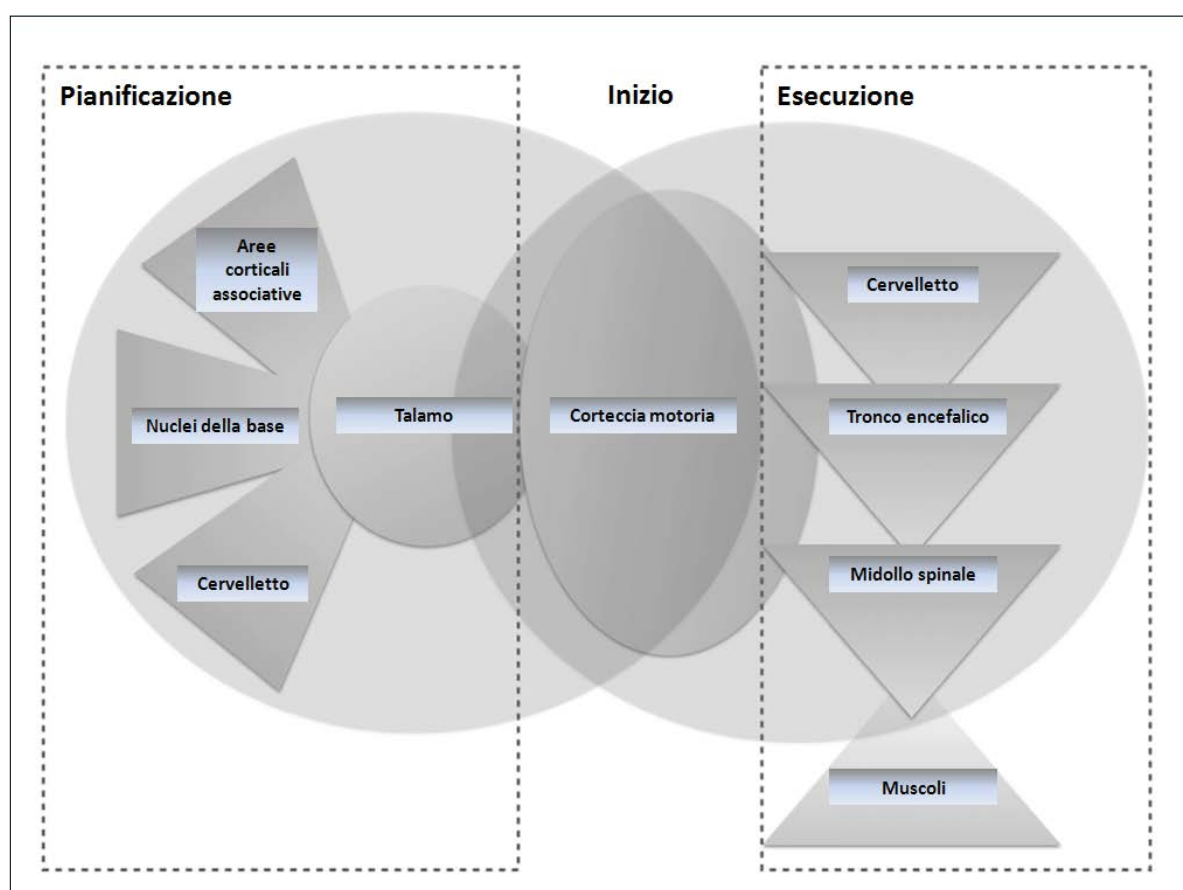

Figura 1. Rappresentazione schematica delle principali aree anatomiche e vie funzionali coinvolte nelle varie fasi del movimento volontario; ci sono molti feedback e concomitanza di stimoli come suggerito dall'alto grado di sovrapposizione tra le diverse aree cerebrali raffigurate (modificata da O'Malley JA, et al. 2017).

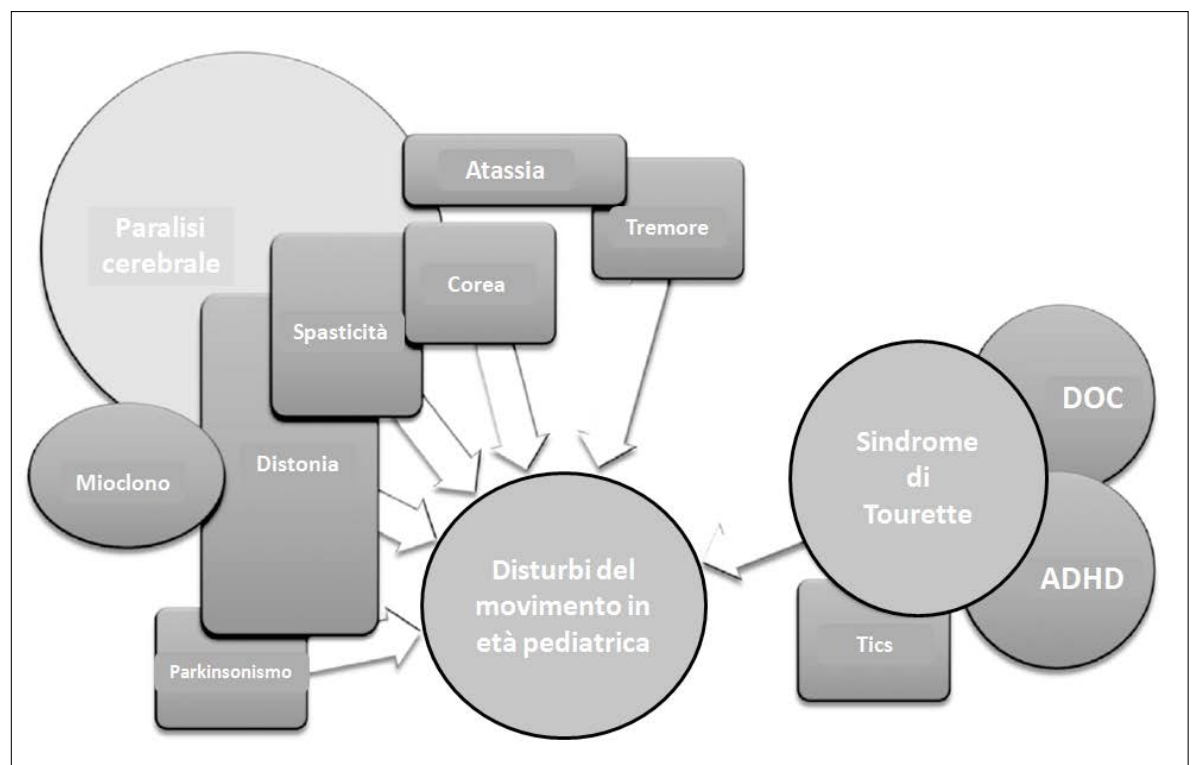

Figura 3. Disturbi del movimento in età pediatrica. DOC (disturbo ossessivo-compulsivo); ADHD (disturbo da deficit di attenzione con iperattività) (modificata da Russ JB, et al. 2018).

con progressiva riduzione/scomparsa dei riflessi primitivi e comparsa dei riflessi posturali (Figura 2). I disturbi del movimento in età pediatrica comprendono una serie di sindromi neurologiche caratterizzate da alterazioni interessanti il tono muscolare, la postura, l'inizio o il controllo della motricità volontaria, o dalla presenza di movimenti involontari. Le anomalie motorie presenti nei disturbi del movimento non vengono determinate da debolezza o alterazioni del tono muscolare, anche se l'ipostenia e le variazioni patologiche del tono muscolare possono essere presenti. I disturbi del movimento vengono convenzionalmente suddivisi in due principali categorie: i disturbi del movimento di tipo ipercinetico (es. distonia, corea, atetosi, ballismo, mioclono, tremore, tic, stereotipie motorie) e i disturbi del movimento di tipo ipocinetico (es. parkinsonismo). È poi possibile classificare i disturbi del movimento in base all'eziologia ( $\mathrm{di}^{-}$ sturbi del movimento acquisiti/sintomatici, forme geneticamente determinate/idiopatiche e disturbi del movimento psicogenetici) e in base all'andamento clinico del disturbo nel tempo (disturbi del movimento transitori/benigni dell'infanzia, disturbi del movimento a esordio acuto, disturbi del movimento ad andamento cronico e disturbi del movimento parossistici). Si possono osservare nel bambino più disturbi del movimento in associazione (es. bambini con paralisi

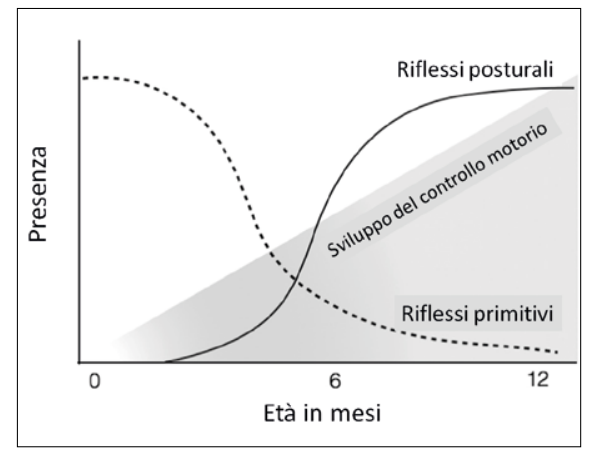

Figura 2. II controllo motorio si sviluppa in parallelo con i processi di mielinizzazione del sistema nervoso centrale e periferico e procede secondo una gradiente rostro-caudale; tale processo è accompagnato da una graduale scomparsa dei riflessi primitivi e dall'emergenza e progressivo consolidamento dei riflessi posturali (modificata da O'Malley JA, et al. 2017). 
cerebrale infantile che spesso presentano in combinazione ipostenia, spasticità, distonia, coreoatetosi e atassia) (Figura 3). La valutazione dei disturbi del movimento può essere un'impresa difficile, specie nel bambino, e richiede esperienza e spesso una specifica competenza clinica. La conoscenza di questo grosso capitolo della neurologia pediatrica è presupposto fondamentale per affrontare correttamente il percorso diagnosticoterapeutico di queste condizioni.

\section{Le due principali categorie di disturbi del movimento}

Disturbi del movimento di tipo ipercinetico I disturbi del movimento di tipo ipercinetico sono movimenti involontari o movimenti in eccesso determinati da una disfunzione interessante i nuclei della base, la corteccia cerebrale, il cervelletto e altri circuiti motori secondaria a una patologia statica o progressiva (es. paralisi cerebrale infantile forma discinetica, malattia degenerativa, ecc.) (Sanger TD, et al. 2003). Disturbi del movimento di tipo ipercinetico benigni possono essere osservati in bambini che non hanno alcuna patologia neurologica.

\section{Distonia}

La distonia è un disturbo del movimento in cui contrazioni muscolari involontarie sostenute o intermittenti determinano torsione e movimenti ripetitivi, posture anomale o entrambi (Sanger TD, et al. 2003). La presenza di posture anomale che sono superimposte al movimento volontario o lo sostituiscono è una caratteristica distintiva della distonia. Le posture distoniche sono spesso scatenate dai tentativi di compiere un movimento volontario o di assumere volontariamente una postura e in alcuni casi si manifestano esclusivamente assumendo determinate posizioni o compiendo specifici movimenti (es. distonia task-specifica); i movimenti e le posture distoniche non si osservano in sonno. I meccanismi che determinano il rilassamento muscolare sono spesso compromessi nei pazienti affetti da distonia e ciò favorisce il mantenimento della postura distonica anche dopo il termine del tentativo di motilità volontaria che l'ha determinata. La distonia può essere causata da lesioni a livello dei nuclei della base, in particolare il putamen e il globo pallido; in molti casi tuttavia non sono riscontrabili lesioni a livello di tali strutture; alterazioni funzionali interessanti il cervelletto, il tronco encefalico e le aree corticali sensoriali possono determinare una distonia; lesioni cortico-spinali possono causare posture fisse simili per caratteristiche alle posture distoniche attraverso meccanismi che determinano la simultanea contrazione di gruppi muscolari antagonisti. La condizio- ne più comunemente responsabile di distonia nel bambino è rappresentata dalle paralisi cerebrali di tipo discinetico determinate da lesioni a livello dei nuclei della base, del talamo, del tronco encefalico o del cervelletto, conseguenza di un danno ipossico-ischemico nel periodo pre-/perinatale; altre cause di distonia includono le encefaliti, le malattie vascolari, autoimmuni, metaboliche e neurodegenerative; le distonie primarie sono forme in prevalenza geneticamente determinate (Tabella 1 )

\section{Corea, ballismo, atetosi}

Corea, ballismo e atetosi sono disturbi ipercinetici del movimento che spesso coesistono nello stesso paziente e che vengono considerati come una serie in continuità. La corea è caratterizzata dalla presenza di sequenze casuali di uno o più movimenti o frammenti di movimento involontari (Sanger TD, et al. 2010) che presentano un'ampia variabilità in durata, direzionalità e distribuzione anatomica e che conferiscono al pattern motorio caratteristiche di imprevedibilità continua; i bambini con corea appaiono all'osservazione come irrequieti e in continuo movimento; il termine deriva dal greco $\chi 0 \rho \varepsilon i ́ \alpha$ che ha il significato di "danza corale". La corea è frequentemente associata ad atetosi (coreoatetosi) che si caratterizza per la presenza di movimenti lenti, continui, involontari determinanti contorsione (writhing movements), prevalentemente distali e che impediscono il mantenimento di una postura stabile. La corea si distingue dall'atetosi perché nella prima è possibile rilevare movimenti distinti o frammenti di movimento mentre nella seconda il movimento appare continuo, fluente, sinuoso; a differenza della corea nell'atetosi le stesse regioni corporee sono ripetutamente coinvolte dal disturbo del movimento; l'atetosi interessa frequentemente le estremità distali degli arti (mani e piedi) e può anche coinvolgere il volto, il collo e il tronco. Il ballismo si definisce come un movimento di tipo coreico che interessa prevalentemente le articolazioni prossimali come spalla o anca e che determina movimenti delle estremità di grande ampiezza. Nei bambini la più frequente causa di corea a esordio acuto è la corea determinata da cause infettive/autoimmuni mentre la causa più frequente di corea ad andamento cronico è rappresentata dalle paralisi cerebrali infantili di tipo discinetico. In generale le coree geneticamente determinate sono croniche, si sviluppano in maniera graduale e sono di tipo generalizzato/simmetrico mentre le coree acquisite spesso esordiscono in maniera acuta o subacuta e quando correlate a lesioni interessanti il sistema nervoso centrale possono essere asimmetriche/unilaterali.

\section{Atassia}

Il termine atassia si riferisce a una compromissione del controllo o della coordinazione dei movimenti volontari non attribuibile a ipostenia o alla presenza di movimenti involontari (es. distonia, corea, mioclono, ecc.). Alla valutazione clinica i bambini con atassia possono manifestare tutta una serie di segni neurologici dipendenti dalla patologia di base. I segni neurologici possono includere anomalie dei movimenti oculari (es. dismetria dei movimenti saccadici, nistagmo, aprassia oculo-motoria), alterazioni del linguaggio di tipo articolatorio (disartria cerebellare), scarsa accuratezza e coordinazione nei movimenti intenzionali finalizzati (dismetria, tremore intenzionale), scarsa stabilità della posizione della testa e del tronco durante la posizione seduta (titubazioni) e un'andatura caratterizzata da instabilità, base d'appoggio allargata e deviazioni dalla direzione rettilinea del cammino. L'atassia a esordio acuto o subacuto ha in genere un'eziologia correlata a fattori infettivi, tossici, autoimmuni, traumatici o neoplastici. L'atassia intermittente può essere un sintomo di un errore congenito del metabolismo o l'espressione di una condizione episodica geneticamente determinata. Un'atassia ad andamento cronico non progressivo può essere la manifestazione clinica di una malformazione cerebellare congenita o di un'alterazione del neurosviluppo su base genetica, mentre le atassie croniche ad andamento progressivo si manifestano generalmente nel contesto di patologie neurodegenerative. È molto importante tenere bene in mente alcune considerazioni pratiche nella valutazione di un bambino che ci viene segnalato per una sospetta atassia. La prima domanda da porsi è se l'atassia sia di fatto il principale disturbo motorio. Per esempio un bambino con goffagine e disturbo dell'equilibrio causato da una corea o da una distonia potrebbe apparire falsamente atassico a una valutazione poco attenta. Allo stesso modo, un mioclono multifocale potrebbe simulare all'apparenza un tremore d'azione e portare a un'erronea diagnosi di dismetria durante i movimenti di precisione finalizzati al raggiungimento di oggetti. Un secondo punto da tenere sempre in considerazione è che l'atassia nei bambini spesso si verifica in combinazione con altre alterazioni motorie come per esempio la spasticità e la distonia; un bambino con un'andatura atasso-spastica potrà per esempio avere una base d'appoggio normale o ristretta invece che allargata, camminare sulle punte e presentare rigidità a livello degli arti inferiori in aggiunta all'instabilità del cammino.

\section{Mioclono}

Il mioclono consiste in movimenti molto rapidi, "shock-like", in sequenze ripetute 
TABELLA 1. Classificazione delle distonie in base alle caratteristiche cliniche e all'eziologia (modificata da Albanese A, et al. 2013).

\section{CARATTERISTICHE CLINICHE}

Distribuzione corporea Focale: interessante una singola regione del corpo.

Segmentale: interessante due o più regioni contigue del corpo.

Multifocale: interessante due o più regioni non contigue del corpo.

Generalizzata: interessante il tronco e almeno altre due regioni.

Emidistonia: interessante più regioni confinate a un emilato corporeo.

Pattern temporale

Tipo di decorso:

statico;

progressivo.

Variabilità:

persistente: distonia persistente durante tutto il giorno con approssimativamente la stessa intensità;

azione-specifica: distonia che si verifica esclusivamente durante alcune attività 0 task motori;

diurna: distonia che fluttua durante il giorno con riconoscibili variazioni circadiane;

parossistica: episodi distonici improvvisi e autolimitati generalmente indotte da un fattore trigger con conseguente ripristino dello stato neurologico preesistente.

Caratteristiche

associate

Isolata o in combinazione ad altri disturbi del movimento:

- isolata: la distonia è l'unico disturbo del movimento presente a eccezione del tremore;

in combinazione ad altri disturbi del movimento: la distonia è associata ad altri disturbi del movimento (es. mioclono, parkinsonismo, ecc.).

Occorrenza di altre manifestazioni neurologiche 0 sistemiche.

\section{EZIOLOGIA}

Condizione patologica interessante il sistema nervoso centrale

Ereditaria 0 acquisita

con perdita di neuroni)

Evidenza di lesioni strutturali (spesso di tipo statico)

Nessuna evidenza di condizione degenerativa o lesione strutturale.

Forme ereditarie (distonie geneticamente determinate):

autosomiche dominanti: distonia come manifestazione clinica predominante (TOR1A, GCH1, THAP1, GNAL); distonia come manifestazione clinica associata o secondaria (MR1, PRRT2, SGCE, ATP1A3, SLC2A1, ATN1, FXN, HTT, SLC2OA2, FTL, ATXN3, TBP);

autosomiche recessive: distonia come manifestazione clinica predominante $(T H, S P R)$; distonia come manifestazione clinica associata o secondaria (DDC, ATM, VPS13A, FUCA1, GCDH, PLA2G6, PRKN, ATP13A2, MUT, MMADHC, NPC1, NPC2, PANK2, HEXA, ATP7B, DCAF17);

$X$-linked recessive: distonia come manifestazione clinica associata 0 secondaria (TAF1, HPRT, TIMM8A, PLP1, MECP2);

mitocondriali: distonia come manifestazione clinica associata o secondaria (mutazioni interessanti diversi geni mitocondriali o nucleari).

Forme acquisite (distonia determinata da causa specifica):

cerebrovascolare (infarto o emorragia);

sofferenza perinatale;

danno traumatico a livello del sistema nervoso centrale;

infezioni;

farmaci;

fattori tossici;

cause neoplastiche;

disturbo psicogenetico.

Forme idiopatiche

Sporadiche.

Familiari.

e spesso non ritmiche, dovuti a improvvisa contrazione (mioclono positivo) o rilassamento (mioclono negativo) di uno o più muscoli. Il mioclono può essere sincrono (diversi muscoli che si contraggono simultaneamente), che diffonde (diversi muscoli che si contraggono in una sequenza prevedibile) o asincrono (diversi muscoli che si contraggono con un tempo di attivazione variabile e non prevedibile). Quando il mioclono interessa più di un muscolo secondo un pattern di attivazione random/variabile viene defini- to "multifocale", mentre si definisce "generalizzato" quando più muscoli vengono coinvolti simultaneamente. Quando il mioclono presenta una frequenza ritmica si definisce "tremore mioclonico"; nel tremore mioclonico si distingue una fase rapida e una fase di recupero dalla contrazione più lenta; la fase rapida può essere dovuta $o$ alla contrazione $o$ al rilassamento muscolare. Il mioclono può essere causato o aggravato dal movimento e può essere a volte presente durante il sonno. In relazione alla condizione in cui si manifesta il mioclono può essere categorizzato in "mioclono d'azione", "mioclono posturale" e "mioclono a riposo". Il mioclono può anche essere categorizzato in relazione alla presunta regione anatomica di origine in "corticale", "sottocorticale", "tronco-encefalico", "propriospinale" o "spinale"; il "mioclono palatale" (definito da alcuni "tremore palatale" per la sua caratteristica frequenza ritmica) è un tipo particolare di mioclono tronco encefalico con interessamento della muscolatura faringea. Per la classificazione del mioclono in base all'eziologia è utile fare riferimento allo schema proposto da Marsden CD, et al. 1983. La classificazione di Marsden utilizza quattro principali categorie: fisiologico, essenziale, epilettico e sintomatico. Il mioclono fisiologico si manifesta in persone sane e il livello di intensità può variare a seconda dell'individuo; sia la storia clinica che la valutazione del paziente possono essere suggestivi di tale condizione; il mioclono può verificarsi come fenomeno fisiologico durante il sonno; le mioclonie ipniche si manifestano come "jerks" generalizzati in prossimità dell'addormentamento e sono un classico esempio di mioclono fisiologico; le reazioni di soprassalto ("startle") e il singhiozzo sono altri esempi di mioclono fisiologico. Il mioclono essenziale si verifica in una serie di condizioni relativamente non progressive e può associarsi a lieve disabilità; all'interno di questa categoria si distinguono forme ereditarie e forme sporadiche; la sindrome mioclono-distonia è tra le forme ereditarie un'entità molto ben definita. Il mioclono epilettico si verifica in diverse sindromi epilettiche in cui le crisi miocloniche rappresentano le manifestazioni cliniche maggiori; le crisi miocloniche dell'epilessia mioclonica giovanile sono un esempio paradigmatico di manifestazioni miocloniche di tipo epilettico; le epilessie miocloniche progressive si caratterizzano per la presenza di un deterioramento cognitivo progressivo, per un mioclono che determina compromissione motoria e che risulta resistente al trattamento antiepilettico, per la presenza di segni cerebellari e per un caratteristico rallentamento progressivo dell'attività elettrica cerebrale all'esame EEG. Il mioclono sintomatico rappresenta la categoria più vasta e comprende una serie 
TABELLA 2. Classificazione del tremore in base alle condizioni attivanti.

\begin{tabular}{|c|c|c|}
\hline TIPO DI TREMORE & DEFINIZIONE & CARATTERISTICHE CLINICHE E MANOVRE ATTIVANTI \\
\hline \multicolumn{3}{|c|}{ Tremore a riposo } \\
\hline & $\begin{array}{l}\text { Si manifesta in parti del corpo completamente sup- } \\
\text { portate, rilassate e non attivate volontariamente. }\end{array}$ & $\begin{array}{l}\text { Il paziente è sdraiato a letto o seduto con la parte del corpo interessa- } \\
\text { ta dal tremore supportata. II tremore è spesso accentuato dallo svol- } \\
\text { gimento di compiti cognitivi o di azioni motorie che coinvolgano altre } \\
\text { parti del corpo ed è spesso soppresso, anche se solo temporaneamen- } \\
\text { te, dalla contrazione muscolare volontaria. }\end{array}$ \\
\hline \multicolumn{3}{|c|}{ Tremore in azione } \\
\hline $\begin{array}{l}\text { Tremore cinetico } \\
\text { (semplice, intenzionale } \\
\text { e task-specifico) }\end{array}$ & $\begin{array}{l}\text { Si verifica durante i movimenti volontari. II tremore } \\
\text { intenzionale si accentua quando la parte del corpo } \\
\text { interessata si avvicina al target da raggiungere. }\end{array}$ & $\begin{array}{l}\text { Es. prova indice-naso, prova tallone-ginocchio, raggiungimento di un } \\
\text { oggetto, scrivere, disegnare, versare dell'acqua in un bicchiere, man- } \\
\text { giare con le posate, parlare, ecc. }\end{array}$ \\
\hline Tremore posturale & $\begin{array}{l}\text { Si verifica nel tentativo di mantenere una specifica } \\
\text { postura o posizione contro la forza di gravità. }\end{array}$ & $\begin{array}{l}\text { Es. l'estendere le braccia orizzontalmente, sedere senza alcun suppor- } \\
\text { to per il tronco, stare in piedi, mantenere protrusa la lingua fuori dalla } \\
\text { bocca, ecc. }\end{array}$ \\
\hline Tremore isometrico & $\begin{array}{l}\text { Si verifica durante una contrazione muscolare con un } \\
\text { oggetto rigido, non mobile. }\end{array}$ & $\begin{array}{l}\text { Es. nello spingere contro un muro, flettere il polso contro un tavolo, } \\
\text { stringere il pugno, ecc. }\end{array}$ \\
\hline
\end{tabular}

TABELLA 3. Più comuni forme di tremore.

\begin{tabular}{|l|}
\hline \multicolumn{1}{|c|}{ Tremore a riposo } \\
\hline Malattia di Parkinson \\
\hline Sindromi parkinsoniane \\
\hline Tremore mesencefalico (rubral tremor) \\
\hline Malattia di Wilson \\
\hline Tremore essenziale di grado severo \\
\hline \\
\hline Accentuazione del tremore fisiologico (es. tremore indotto da farmaci o da sostanze tossiche) \\
\hline Tremore essenziale \\
\hline Tremore task-specifico \\
\hline Altri disturbi extrapiramidali (es. malattia di Parkinson, malattia di Wilson, distonia) \\
\hline Patologie interessanti in cervelletto \\
\hline Tremore neuropatico \\
\hline \\
\hline Patologia cerebellare \\
\hline Sclerosi multipla \\
\hline Stroke a livello mesencefalico \\
\hline Trauma a livello mesencefalico \\
\hline
\end{tabular}

di condizioni a varia eziologia comunemente associate ad altri segni e sintomi neurologici come la demenza, il delirio e altri disturbi del movimento.

\section{Tremore}

Il tremore è un movimento involontario che si caratterizza per oscillazioni ritmiche intorno a un asse fisso. La velocità dei movimenti oscillatori risulta simmetrica e determina rispetto all'asse di movimento un pattern sinusoidale. Il tremore è spesso, ma non sempre, determinato da contrazioni ritmiche alternate di coppie di gruppi muscolari antagonisti. In base alle condizioni attivanti è possibile distinguere da un punto di vista clinico forme di tremore a riposo che si verificano in parti del corpo completamente (si manifesta durante la contrazione muscolare contro un oggetto fermo come ad esempio quando si stringe qualcosa). Il tremore può anche essere classificato a seconda della distribuzione anatomica in focale (quando interessa solo una parte del corpo come per esempio le strutture fonatorie, la testa, la mandibola o un arto), segmentale (quando sono coinvolte due o più parti del corpo contigue nella parte superiore o inferiore del corpo come testa e braccio), emitremore (quando è interessato un emilato del corpo) e generalizzato (quando sono coinvolti la parte superiore e inferiore del corpo). A seconda dell'eziologia è possibile distinguere forme genetiche, acquisite e idiopatiche. Le più comuni forme di tremore a riposo e in azione vengono elencati nella Tabella 3. Il tremore è meno comune nei bambini rispetto agli adulti; le cause più comuni di tremore in età pediatrica sono rappresentate da condizioni ereditarie (es. tremore essenziale), cause metaboliche (es. ipertiroidismo, squilibri elettrolitici), utilizzo di farmaci (es. acido valproico), malattie degenerative (es. malattia di Wilson), lesioni focali (es. tremore mesencefalico, tremore di Holmes), tremore psicogenetico e tremore fisiologico (accentuazione del tremore fisiologico). riamente da forme di tremore in azione che si rilevano in occasione di contrazioni muscolari volontarie (Tabella 2). Il tremore in azione viene a sua volta distinto in tremore cinetico (tremore cinetico semplice in cui il tremore è grosso modo lo stesso durante tutta l'attività motoria volontaria, tremore intenzionale in cui si assiste a un aumento in crescendo del tremore quando la parte del corpo interessata si avvicina al target da raggiungere e tremore task-specifico che si manifesta solo in occasione di specifiche attività motorie come per esempio scrivere); tremore posturale (si manifesta quando viene volontariamente mantenuta una postura o posizione come per esempio mantenere le braccia estese in avanti) e tremore isometrico

\section{Tic}

I tic sono movimenti, frammenti di movimento o vocalizzazioni, ripetitivi, individualmente riconoscibili e intermittenti, che possono essere soppressi solo per brevi intervalli di tempo; il soggetto che ne è affetto tipicamente percepisce un forte impulso di mettere in atto il tic. Elementi caratteristici sono rappresentati dalla prevedibilità del tipo di movimento e del suo inizio, l'accentuazione/aumento della frequenza del disturbo del movimento durante stati di eccitazione o stress, dalla possibilità di poter inibire i tic per brevi intervalli di tempo con sensazione di 
TABELLAA 4. Caratteristiche chiave dei disturbi ipercinetici del movimento.

\begin{tabular}{|c|c|c|c|c|}
\hline & Ritmicità & Posture ripetute & Movimenti ripetitivi stereotipati & Sopprimibilità \\
\hline $\begin{array}{l}\text { Distonia } \\
\text { Corea } \\
\text { Atetosi } \\
\text { Mioclono } \\
\text { Tremore } \\
\text { Tics } \\
\text { Stereotipie }\end{array}$ & $\begin{array}{l}\text { Raramente } \\
\text { No } \\
\text { No } \\
\text { A volte } \\
\text { Sì } \\
\text { No } \\
\text { Sì }\end{array}$ & $\begin{array}{l}\text { Sì } \\
\text { No } \\
\text { No } \\
\text { A volte } \\
\text { No } \\
\text { Sì } \\
\text { A volte }\end{array}$ & $\begin{array}{l}\text { A volte } \\
\text { Raramente } \\
\text { No } \\
\text { Di solito sì } \\
\text { Sì } \\
\text { Sì } \\
\text { Sì }\end{array}$ & $\begin{array}{l}\text { Parzialmente o per breve tempo } \\
\text { No } \\
\text { No } \\
\text { No } \\
\text { Talvolta e per breve tempo } \\
\text { Di solito sì } \\
\text { Sì }\end{array}$ \\
\hline
\end{tabular}

TABELLA 5. Elementi della valutazione clinica e loro correlazione a specifici disturbi del movimento di tipo ipercinetico.

\begin{tabular}{|c|c|c|c|c|c|c|c|}
\hline & Distonia & Corea & Atetosi & Mioclono & Tremore & Tic & Stereotipie \\
\hline Distraibilità & No & No & No & No & No & Sì & Sì \\
\hline Sopprimibilità & Parziale & No & No & No & Per poco tempo & Di solito sì & Sì \\
\hline Durata & Variabile & In crescendo & In crescendo & Shock-like & In crescendo & Variabile & Variabile \\
\hline Velocità & Variabile & Medio-veloce & Lento-medio & $\begin{array}{l}\text { Molto veloce } \\
\text { (<1 secondo) }\end{array}$ & $2-14 \mathrm{~Hz}$ & Variabile & $2-6 \mathrm{~Hz}$ \\
\hline $\begin{array}{l}\text { Movimento } \\
\text { rapido tipo } \\
\text { scatto }\end{array}$ & A volte & A volte & No & Molto & A volte & A volte & Raro \\
\hline $\begin{array}{l}\text { Movimento } \\
\text { stereotipato }\end{array}$ & Spesso & No & No & Di solito sì & Sì & Sì & Sì \\
\hline $\begin{array}{l}\text { Movimento } \\
\text { ritmico }\end{array}$ & A volte & No & No & A volte & Sì & Di solito no & Sì \\
\hline $\begin{array}{l}\text { Movimento } \\
\text { intermittente }\end{array}$ & A volte & A volte & No & A volte & A volte & Sì & Sì \\
\hline $\begin{array}{l}\text { Movimento } \\
\text { in crescendo }\end{array}$ & A volte & Sì & Sì & A volte & Sì & No & Sì \\
\hline $\begin{array}{l}\text { Movimento } \\
\text { fluido }\end{array}$ & No & Sì & Sì & No & No & A volte & A volte \\
\hline $\begin{array}{l}\text { Presenza } \\
\text { di piccoli } \\
\text { movimenti } \\
\text { inscritti }\end{array}$ & No & Sì & Forse & No & No & A volte & No \\
\hline Contesto & $\begin{array}{c}\text { Movimento } \\
>\text { riposo }\end{array}$ & $\begin{array}{l}\text { Movimento } \\
\text { > riposo }\end{array}$ & $\begin{array}{c}\text { Riposo } \\
>\text { movimento }\end{array}$ & Tutti & Variabile & A riposo & A riposo \\
\hline Prevedibile & A volte & No & No & No & No & Sì & $\begin{array}{c}\text { Spesso non } \\
\text { consapevole }\end{array}$ \\
\hline $\begin{array}{l}\text { Pattern moto- } \\
\text { rio normale }\end{array}$ & A volte & Sì & Sì & No & Sì & Sì & Sì \\
\hline
\end{tabular}

disagio da parte del paziente. In molti bambini il tentativo di sopprimere un tic determina una crescente urgenza di mettere in atto il movimento spesso preceduta da una premonizione di tipo sensoriale. C'è un'alta comorbidità tra tic e disturbo ossessivo compulsivo e talvolta è difficile distinguere i tic motori complessi dai comportamenti di tipo compulsivo. I tic vengono classificati in due grandi categorie (motori e vocali) e all'interno di queste in due gruppi (semplici e complessi). I tic motori semplici coinvolgono un singolo muscolo o un gruppo di muscoli localizzato (es. ammiccamenti palpebrali, movimenti del capo, movimenti di sollevamento della spalla). I tic motori complessi (movimenti o sequenze di movimento che coinvolgono più gruppi muscolari) possono essere movimenti non finalizzati (es. movimenti del volto o del corpo) o movimenti apparentemente finalizzati, ma che di fatto non hanno uno scopo in quel determinato contesto (es. toccare, colpire, odorare, saltare, rannicchiarsi, imitare movimenti osservati [ecoprassia], compiere gesti osceni [coproprassia]). I tic vocali semplici consistono nella produzione di vari suoni e rumori (es. grugniti, colpi di tosse, grida, urla, gemiti, annusare/tirare su con il naso, schiarirsi la voce). I tic vocali complessi comprendono vocalizzazioni ed espressioni verbali aventi significato; le verbalizzazioni possono includere la ripetizione di parole, sillabe o frasi (ecolalia [ripetizione delle parole sentite da altri], palilalia [ripetizione delle proprie parole]) o la produzione di parole oscene/profane [coprolalia]).

Un disturbo da tic si definisce transitorio quando i tic (motori o vocali) esordiscono in un individuo prima del compimento dei 18 anni e durano meno di un anno; il disturbo non può essere attribuito a problematiche di tipo psicologico, all'utilizzo di sostanze o farmaci o a una specifica patologia (es. malattia neurodegenerativa, sindrome neuro cutanea, ecc.). Si parla invece di disturbo da tic cronico quando i tic (motori o vocali, ma non entrambi) esorditi in un individuo di età inferiore ai 18 anni durano più di un anno; anche in questo caso i tic non possono essere attribuiti all'uso di sostanze/farmaci o a specifica patologia. 
La sindrome di Tourette è un disturbo neuropsichiatrico complesso caratterizzato dalla presenza di tic multipli di tipo motorio e di almeno un tic vocale con esordio prima dei 18 o 21 anni (a seconda di quali criteri diagnostici vengano utilizzati); la diagnosi è spesso supportata dalla presenza di anomalie comportamentali che includono il disturbo da deficit di attenzione con iperattività (ADHD) e il disturbo ossessivo-compulsivo o altre problematiche psichiatriche (es. disturbo d'ansia, disturbo dell'umore, disturbo della condotta, ecc.); una storia familiare con sintomi simili può essere di supporto alla diagnosi di questa condizione.

\section{Stereotipie}

Le stereotipie sono movimenti ripetitivi semplici che possono essere interrotti volontariamente. Le stereotipie sono tipicamente dei movimenti in avanti e all'indietro come per esempio l'agitare o il battere le mani o le braccia e non si manifestano con movimenti o frammenti di movimento di tipo complesso. I movimenti sono spesso, ma non sempre, ritmici e possono coinvolgere le dita, i polsi o le regioni più prossimali degli arti superiori; gli arti inferiori tipicamente non vegono interessati. Le stereotipie possono essere unilarerali o bilaterali, ma sono più comunemente bilarerali. Probabilmente non c'è sensazione di urgenza che precede il disturbo del movimento e si verificano sia che il bambino sia stressato, eccitato, distratto o impegnato. Le stereotipie possono essere interrotte dalla distrazione o dall'inizio di un'altra attività. In genere non interferiscono significativamente con lo svolgimento delle attività in corso, anche se possono transitoriamente interromperle. Sebbene le stereotipie abbiano inizio e fine chiari la durata può essere variabile, anche di diversi minuti, fino a quando il bambino non venga distratto con un'altra attività. Le stereotipie si manifestano spesso in bambini con alterazioni del neurosviluppo, tra cui i disturbi dello spettro autistico, ma possono verificarsi anche in bambini neurotipici, tipicamente in età prescolare. Quindi la presenza di stereotipie motorie non è di per sé diagnostica o predittiva di patologia neurologica e risulta scarsamente informativa rispetto alla prognosi e poco orientativa rispetto alle possibili diagnosi differenziali nell'ambito dei disturbi del neurosviluppo.

Disturbi del movimento di tipo ipocinetico I disturbi del movimento di tipo ipocinetico si caratterizzano per una riduzione dell'attività motoria e sono spesso associati a rigidità, instabilità posturale e a perdita dei movimenti automatici associati ai normali pattern motori. Anche in queste condizioni la diagnosi trova il suo principale cardine nell'at- tenta osservazione delle caratteristiche cliniche del disturbo del movimento (Jankovic J, et al. 2016). I disturbi ipocinetici del movimento sono piuttosto rari nel bambino e verranno discusse le forme più comuni (malattia di Parkinson, malattia di Wilson, malattia di Huntington e neurodegenerazione con accumulo intracerebrale di ferro).

La malattia di Parkinson e i parkinsonismi a varia eziologia rappresentano l'esempio emblematico dei disturbi ipocinetici del movimento; queste condizioni si caratterizzato per la presenza di lentezza nel movimento, tremore a riposo, rigidità e disturbo dell'andatura; i sintomi non motori includono deficit olfattivo, problematiche comportamentali, deficit di tipo cognitivo, disturbi del sonno e disfunzioni autonomiche. La malattia di Parkinson tipicamente si manifesta in età avanzata, tuttavia forme a esordio precoce possono verificarsi al di sotto dei 40 anni; se la malattia si manifesta prima del compimento dei 20 anni si parla di forma giovanile. La malattia di Wilson (degenerazione epatolenticolare) è una condizione trattabile, causa di parkinsonismo giovanile, distonia, tremore e altri disturbi del movimento. È determinata da mutazioni a carico del gene $A T P 7 B$ che causano una riduzione del trasporto del rame dagli epatociti alla bile, con conseguente accumulo di rame a livello del fegato e di altri tessuti incluso il sistema nervoso centrale.

La malattia di Huntington si manifesta tipicamente nella quarta-quinta decade di vita, tuttavia l'esordio dei sintomi si verifica durante l'infanzia o l'adolescenza approssimativamente nel 5-7\% dei pazienti affetti. I pazienti con malattia di Huntington a esordio giovanile sviluppano distonia, atassia e crisi epilettiche; alcuni di questi sviluppano una sindrome acinetico-rigida denominata variante Westphal. Nel bambino con malattia di Huntington la progressione di patologia è più rapida rispetto a quanto si verifica nell'adulto. $\mathrm{La}$ neurodegenerazione con accumulo intracerebrale di ferro (NBIA) è rappresentata da uno spettro di condizioni fenotipicamente sovrapponibili da un punto di vista clinico, ad andamento progressivo, caratterizzate dalla presenza di parkinsonismo, distonia, deterioramento cognitivo e altri possibili deficit neurologici. Si distinguono diverse forme determinate da meccanismi eziopatogenetici differenti (Tabella 6).

\section{I disturbi del movimento classificati in base all'eziologia e all'andamento clinico nel tempo}

Disturbi del movimento nelle condizioni caratterizzate da alterazione del neurosviluppo I disturbi del neurosviluppo sono rappresentati da un gruppo di condizioni che si mani-

\begin{tabular}{l}
\hline TABELLA 6. Condizioni \\
determinanti neurodegenerazione \\
con accumulo intracerebrale \\
di ferro (NBIA). \\
\hline - Neurodegenerazione associata a deficit di \\
pantotenato chinasi. \\
- Distrofia neuroassonale infantile. \\
- Neurodegenerazione associata a disfunzione \\
- delle proteine di membrana mitocondriali. \\
- Neurodegenerazione associata alle proteine \\
- beta-propeller. \\
- Neurodegenerazione associata a deficit di \\
- Sindrome di Kufor-Rakeb. \\
- Neuroferritinopatia. \\
- Aceruloplasminemia. \\
- Sindrome di Woodhouse-Sakati. \\
- NBIA da causa sconosciuta. \\
\hline
\end{tabular}

festano clinicamente nelle fasi piuttosto precoci dello sviluppo del bambino e che spesso determinano una compromissione funzionale in diverse aree del funzionamento adattivo (personale, sociale, scolastico e lavorativo). I disturbi del neurosviluppo comprendono, secondo la classificazione del manuale diagnostico e statistico dei disturbi mentali quinta edizione (DSM-5), la disabilità intellettiva, i disturbi della comunicazione, i disturbi dello spettro autistico, il disturbo da deficit di attenzione/iperattività (ADHD), i disturbi specifici di apprendimento e i disturbi motori. Più disturbi del neurosviluppo possono coesistere nello stesso bambino (es. bambini con disturbo dello spettro autistico con associata disabilità intellettiva o bambini con disturbo da deficit di attenzione/iperattività con associate difficoltà specifiche di apprendimento scolastico, ecc.). In alcuni disturbi del neurosviluppo e nello specifico nei disturbi dello spettro autistico e nelle condizioni caratterizzate dalla presenza di disabilità intellettiva è abbastanza comune rilevare la presenza di disturbi del movimento. Disturbi del movimento comunemente presenti nei disturbi dello spettro autistico o in condizioni associate a disabilità intellettiva sono per esempio rappresentati dalle stereotipie motorie, dai disturbi dell'andatura (es. cammino sulle punte dei piedi, scarso equilibrio, riduzione dei movimenti pendolari degli arti superiori durante il cammino), disprassia e posture anomale (es. posture anomale del capo, tronco e arti, "W-sitting", ecc.). Il cammino sulle punte, condizione di comune riscontro nella pratica clinica, può dipendere da anomalie strutturali (es. contrattura tendinea, discrepanza nella lunghezza degli arti inferiori, ecc.), da alterazioni del neurosviluppo/neurologiche/neuromuscolari (es. disturbi dello spettro autistico, paralisi cerebrale infantile, distrofia muscolare, ecc.) o è più comunemente idiopatico (si rileva in bambini sani e non risulta riconducibi- 
le ad alcuna causa con l'applicazione degli strumenti diagnostici disponibili); un'attenta valutazione clinica comprensiva di esame obiettivo generale e neurologico unitamente a specifici esami strumentali, se indicati, consentono il raggiungimento di una corretta diagnosi e di scegliere il trattamento più idoneo per questa condizione (Ruzbarsky JJ, et al. 2016).

Disturbi del movimento psicogenetici

I disturbi psicogenetici del movimento sono disturbi del movimento non attribuibili a un'alterazione organica o lesionale del sistema nervoso centrale, ma risultanti invece da una causa psicologica o da una patologia psichiatrica. I disturbi psichiatrici più frequentemente associati a disturbo psicogenetico del movimento sono la depressione maggiore, il disturbo d'ansia, i disturbi somatoformi, i disturbi di personalità e il disturbo fittizio. I disturbi psicogenetici del movimento vanno distinti dalla simulazione, condizione in cui un soggetto finge un disturbo motorio per ottenere un vantaggio secondario. I fattori di rischio per l'insorgenza di un disturbo psicogenetico del movimento sono spesso eventi particolarmente stressanti dal punto di vista emozionale/psichico (es. abusi sessuali o violenze, interventi chirurgici, traumi fisici, ecc.). Gli indizi clinici che suggeriscono l'origine psicogenetica di un disturbo del movimento sono ricavabili dall'anamnesi (esordio brusco, rapida progressione fino alla massima gravità, decorso non progressivo con variazioni irregolari nel tempo e aggravamenti improvvisi, remissione spontanea, sintomi inspiegabili dal punto di vista medico), dalla valutazione del paziente (disturbo del movimento inconsistente nel tempo e con caratteristiche incongruenti rispetto ai disordini del movimento di origine organi$\mathrm{ca}$, presenza di più movimenti anomali in associazione, segni sensitivi o motori di natura non organica, mancata risposta a trattamenti specifici, risposta al placebo, remissione dopo trattamento psicologico) e dall'analisi dello specifico disturbo del movimento (variazioni del disturbo del movimento con distrazione/attenzione, risposte paradosso nei confronti di alcune manovre neurologiche, distribuzione atipica delle aree corporee interessate dal disturbo del movimento, ecc.). Un disturbo del movimento psicogenetico non va mai sottovalutato/sminuito rispetto ai disturbi del movimento su base organica ed è sempre fondamentale una valutazione psicologica o psichiatrica finalizzata al raggiungimento di una corretta diagnosi e successivamente a un adeguato trattamento. Evitare il danno iatrogeno derivante dal sottoporre il paziente a esami invasivi non necessari o a trattamenti inappropriati è molto importante. Una chiara spiegazione della natura del disturbo in modo che risulti ben comprensibile sia al bambino/adolescente che ai suoi genitori rappresenta il primo ed essenziale passo verso il trattamento.

Disturbi del movimento transitori/benigni dell'infanzia

I neonati e i bambini possono presentare una serie di disturbi del movimento transitori che tipicamente regrediscono con la crescita. I movimenti anomali possono presentarsi come mioclono, distonia o tremore e sono spesso parossistici. Lo sviluppo psicomotorio e la valutazione neurologica di questi bambini risultano tipicamente normali. Condizioni benigne caratterizzate dalla presenza di mioclono includono per esempio il mioclono neonatale benigno durante il sonno che si verifica esclusivamente quando il bambino dorme e scompare in veglia e il mioclono benigno dell'infanzia che può mimare gli spasmi presenti nella sindrome di West. Una sintomatologia tremorigena può manifestarsi in alcuni neonati con ipereccitabilità (“jitteriness"), stimolo sensibile, o durante la prima infanzia con manifestazioni tipo "brivido" ("shuddering"). Lo spasmus nutans, che si può manifestare in età infantile, si caratterizza per la triade titubazioni del capo ("head nodding" o "head bobbing"), nistagmo e postura anomala del capo (testa ruotata o deviata) (quest'ultimo segno clinico non è sempre presente e osservabile solo nel 30-40\% dei casi); nel caso dello spasmus nutans è indicato effettuare oltre a una visita neurologica, una valutazione oftalmologica comprensiva di studio di elettrofisiologia oculare (potenziali evocati visivi ed elettroretinogramma) e uno studio neuroradiologico per escludere condizioni sintomatiche che clinicamente possono manifestarsi con sintomi analoghi (es. gravi difetti di refrazione, patologie retiniche, glioma del chiasma o del nervo ottico, ipoplasia del verme cerebellare, tumori cerebrali, malattia di Pelizaeus Merzbacher, ecc.). Alcune condizioni transitorie caratterizzate dalla presenza di pattern motori di tipo distonico includono il torcicollo parossistico benigno dell'infanzia (considerato un equivalente emicranico e che si manifesta con episodi periodici di inclinazione del capo con talora associati pallore, vomito, irritabilità o atassia), la distonia idiopatica benigna dell'infanzia (caratterizzata da distonia segmentale a riposo, interessante di solito un braccio, che scompare con i movimenti volontari), la sindrome di Sandifer (caratterizzata dalla presenza di torcicollo o posture in opistotono determinate dal reflusso gastro-esofageo), la masturbazione infantile (caratterizzata dal ripetersi di movimenti stereotipati e/o posture a livello degli arti inferiori) e la deviazione parossistica coniugata degli occhi verso l'alto che può simulare una distonia oculare e che si associa spesso a flessione del capo. Il trattamento di queste condizioni benigne e transitorie non è necessario ed è importante il loro riconoscimento per rassicurare i genitori ed evitare l'effettuazioni di indagini inutili (Bonnet $\mathrm{C}$, et al. 2010; Fernández-Alvarez E. 2018).

Disturbi del movimento a esordio acuto

Un disturbo del movimento a esordio acuto in un bambino sano rende necessaria una valutazione neurologica urgente. È utile avere familiarità con i disturbi del movimento che tipicamente possono esordire acutamente in età pediatrica (Tabella 7). Le condizioni che più frequentemente causano un disturbo del movimento a esordio acuto sono le malattie infettive/infiammatorie/autoimmuni, i farmaci (effetto collaterale o intossicazione) e i disturbi psicogenetici. Un'accurata diagnosi è fondamentale perché molte di queste condizioni sono trattabili. Un disturbo del movimento a esordio acuto può insorgere anche in bambini con un preesistente disturbo del movimento; un esempio di tale circostanza è il peggioramento acuto di una distonia (stato distonico) in un bambino con paralisi cerebrale infantile con caratteristiche distonico/discinetiche; un altro esempio può essere rappresentato dall'insorgenza acuta di una grave corea e ballismo in un bambino con encefalopatia da mutazione del gene GNAO1. In queste ultime due situazioni è spesso necessario un accesso presso un reparto ospedaliero pediatrico, possibilmente provvisto di unità di terapia intensiva, per la gestione in acuto del disturbo.

Disturbi del movimento ad andamento cronico Molti disturbi del movimento che interessano l'età pediatrica hanno un andamento cronico e possono essere geneticamente determinati o acquisiti. Le forme geneticamente determinate rappresentano condizioni rare e fenotipicamente molto diverse tra loro; in alcune forme le caratteristiche distintive di tipo clinico/neurologico e della storia possono fortemente orientare la diagnosi verso una determinata malattia che può poi essere poi confermata da specifici test genetici; in altre sono necessari approfondimenti diagnostici ad ampio spettro (es. esami di screening per patologie metaboliche, test genetici su pannelli specifici per i disturbi del movimento, analisi genetiche mediante tecniche di next-generation sequencing, ecc). Alcuni marker biochimici possono permettere in maniera rapida la diagnosi di specifiche condizioni metaboliche correlate a disturbo del movimento per cui è possibile un trattamento (Tabella 8). Tra le forme acquisite le paralisi cerebrali infantili rappresentano la condizione più comune associata a disturbo del movimento in età pediatrica; la pa- 


\begin{tabular}{|c|c|c|}
\hline Disturbo del movimento & Cause & Commenti \\
\hline \multirow[t]{2}{*}{ Corea } & $\begin{array}{l}\text { Post-streptococcica (corea } \\
\text { di Sydenham), altre encefaliti } \\
\text { autoimmuni }\end{array}$ & $\begin{array}{l}\text { Nell'encefalite con anticorpi anti-N-metil-D-aspartato (NMDA) e in altre encefaliti } \\
\text { autoimmuni il disturbo del movimento è spesso misto (distonia, stereotipie); il tratta- } \\
\text { mento è di tipo immunomodulante. }\end{array}$ \\
\hline & Indotta da farmaci & $\begin{array}{l}\text { Farmaci anticolinergici, dopaminergici (corea acuta), bloccanti dei recettori per la do- } \\
\text { pamina (forma tardiva con spesso associati acatisia e distonia; discinesia da sospen- } \\
\text { sione con movimenti ipercinetici e atassia). }\end{array}$ \\
\hline Distonia & Reazione distonica acuta & $\begin{array}{l}\text { Causata da farmaci che bloccano i recettori dopaminergici, inclusi gli antipsicotici e } \\
\text { gli antiemetici (es. metoclopramide); il trattamento degli episodi acuti consiste nella } \\
\text { somministrazione di farmaci anticolinergici. }\end{array}$ \\
\hline Mioclono & $\begin{array}{l}\text { Sindrome opsoclono- } \\
\text { mioclono-atassia }\end{array}$ & $\begin{array}{l}\text { Può essere associata ad atassia, disturbo del sonno, irritabilità; spesso determinata } \\
\text { dal neuroblastoma; la terapia è immunosoppressiva. }\end{array}$ \\
\hline \multirow[t]{2}{*}{ Atassia } & $\begin{array}{l}\text { Atassia cerebellare } \\
\text { post-infettiva }\end{array}$ & $\begin{array}{l}\text { Può verificarsi in seguito a una malattia infettiva intercorrente o a una vaccinazione; } \\
\text { esordio acuto con recupero completo nel } 90 \% \text { dei casi in un periodo di 2-3 mesi. }\end{array}$ \\
\hline & Intossicazione da farmaci & $\begin{array}{l}\text { Es. antiepilettici, benzodiazepine, antistaminici; tipicamente si associa un'alterazione } \\
\text { del normale stato di reattività/vigilanza. }\end{array}$ \\
\hline \multirow[t]{2}{*}{ Parkinsonismo } & Indotto da farmaci & Causato da farmaci che bloccano i recettori per la dopamina. \\
\hline & Encefalite autoimmune & Condizione rara; associata a lesioni di tipo infiammatorio interessanti i nuclei della base. \\
\hline $\begin{array}{l}\text { Tremore, distonia, } \\
\text { disturbo del cammino }\end{array}$ & $\begin{array}{l}\text { Disturbo psicogenetico } \\
\text { del movimento }\end{array}$ & $\begin{array}{l}\text { Caratteristiche cliniche incongruenti con le forme note di disturbo del movimento; il } \\
\text { trattamento inizia con una corretta comunicazione diagnostica e prosegue con l'affron- } \\
\text { tare le problematiche psicologiche/psichiatriche determinanti il disturbo. }\end{array}$ \\
\hline
\end{tabular}

\section{TABELLA 8. Malattie metaboliche per cui esiste un trattamento che si possono manifestare con disturbo} del movimento in età pediatrica.

\begin{tabular}{|c|c|c|c|c|c|c|}
\hline Condizione & Gene/i & Eta d'esordio & $\begin{array}{l}\text { Caratteristiche } \\
\text { cliniche } \\
\text { principali }\end{array}$ & $\begin{array}{l}\text { Caratteristiche } \\
\text { dell'esame } \\
\text { RM encefalo }\end{array}$ & $\begin{array}{c}\text { Esami di } \\
\text { laboratorio }\end{array}$ & Trattamento \\
\hline $\begin{array}{l}\text { Malattie dei } \\
\text { neurotrasmettitori } \\
\text { (monoamine) }\end{array}$ & $\begin{array}{l}\text { GCH, TH, PTS, } \\
\text { ODPR, SPR, } \\
\text { DDC, DNAJC12 }\end{array}$ & Infanzia & $\begin{array}{l}\text { Ipotonia, distonia, } \\
\text { crisi oculogire, ptosi, } \\
\text { disfunzioni autono- } \\
\text { miche }\end{array}$ & $\begin{array}{l}\text { Generalmente } \\
\text { normale }\end{array}$ & $\begin{array}{l}\text { Alterazioni specifiche } \\
\text { dipendenti dalla } \\
\text { specifica condizione } \\
\text { interessanti i meta- } \\
\text { boliti e le pterine dei } \\
\text { neurotrasmettitori } \\
\text { (monoamine) a livello } \\
\text { liquorale }\end{array}$ & $\begin{array}{l}\text { Somministrazione } \\
\text { del precursore del } \\
\text { neurotrasmetti- } \\
\text { tore carente e in } \\
\text { condizioni specifiche } \\
\text { tetraidrobiopterina e } \\
\text { acido folinico }\end{array}$ \\
\hline $\begin{array}{l}\text { Sindrome da deficit } \\
\text { del trasportatore del } \\
\text { glucosio (GLUT1-DS) }\end{array}$ & SLC2A1 & Infanzia & $\begin{array}{l}\text { Atassia, spasticità, } \\
\text { distonia, discinesia } \\
\text { parossistica indotta } \\
\text { dall'esercizio, crisi } \\
\text { epilettiche, disabilità } \\
\text { intellettiva }\end{array}$ & $\begin{array}{l}\text { Generalmente } \\
\text { normale }\end{array}$ & $\begin{array}{l}\text { Ipoglicorrachia, } \\
\text { glicemia normale, } \\
\text { lattato liquorale } \\
\text { a concentrazioni } \\
\text { basse/normali }\end{array}$ & Dieta chetogena \\
\hline $\begin{array}{l}\text { Ceroidolipofuscinosi } \\
\text { neuronale tipo } 2\end{array}$ & TPP1 & Infanzia & $\begin{array}{l}\text { Ritardo dello sviluppo } \\
\text { del linguaggio, crisi } \\
\text { epilettiche polimorfe } \\
\text { (es. tonico-cloni- } \\
\text { che generalizzate, } \\
\text { miocloniche, } \\
\text { atoniche) e spesso } \\
\text { farmacoresistenti, } \\
\text { deterioramento } \\
\text { cognitivo, regres- } \\
\text { sione dello sviluppo } \\
\text { psicomotorio, disturbi } \\
\text { del movimento (mio- } \\
\text { clono epilettico/non } \\
\text { epilettico, atassia, } \\
\text { distonia, spasticità e } \\
\text { più raramente corea, } \\
\text { atesosi, tremore, par- } \\
\text { kinsonismo), disturbi } \\
\text { del sonno, alterazioni } \\
\text { comportamentali, } \\
\text { ipovisione }\end{array}$ & $\begin{array}{l}\text { Può apparire } \\
\text { normale in fase } \\
\text { precoce di malattia } \\
\text { e successivamente } \\
\text { documentare atrofia } \\
\text { cerebellare o diffusa } \\
\text { con perdita di volume } \\
\text { della sostanza } \\
\text { grigia corticale, } \\
\text { iperintensità a livello } \\
\text { della sostanza bianca } \\
\text { periventricolare nelle } \\
\text { sequenze T2 pesate } \\
\text { o disorganizzazione } \\
\text { della struttura } \\
\text { della sostanza bianca } \\
\text { nelle sequenze in } \\
\text { diffusione }\end{array}$ & $\begin{array}{l}\text { Deficit dell'attività } \\
\text { dell'enzima TPP1 } \\
\text { testabile su leucocici, } \\
\text { fibroblasti o goccia di } \\
\text { sangue essiccata su } \\
\text { filtri di carta bibula }\end{array}$ & $\begin{array}{l}\text { Trattamento di } \\
\text { sostituzione enzi- } \\
\text { matica attraverso la } \\
\text { somministrazione pe- } \\
\text { riodica all'interno del } \\
\text { sistema ventricolare } \\
\text { cerebrale di enzima } \\
\text { ricombinante umano } \\
\text { TPP1 }\end{array}$ \\
\hline
\end{tabular}




\begin{tabular}{|c|c|c|c|c|c|c|}
\hline Condizione & Gene/i & Eta d'esordio & $\begin{array}{c}\text { Caratteristiche } \\
\text { cliniche } \\
\text { principali }\end{array}$ & $\begin{array}{c}\text { Caratteristiche } \\
\text { dell'esame } \\
\text { RM encefalo }\end{array}$ & $\begin{array}{l}\text { Esami di } \\
\text { laboratorio }\end{array}$ & Trattamento \\
\hline $\begin{array}{l}\text { Deficit cerebrale di } \\
\text { folati }\end{array}$ & $F O L R 1^{*}$ & Infanzia & $\begin{array}{l}\text { Ipotonia, ritardo dello } \\
\text { sviluppo psicomo- } \\
\text { torio, irritabilità, } \\
\text { atassia, spasticità, } \\
\text { corea, distonia, crisi } \\
\text { epilettiche }\end{array}$ & $\begin{array}{l}\text { Atrofia frontotem- } \\
\text { porale, ipeintensità } \\
\text { nelle immagini T2 } \\
\text { pesate a livello } \\
\text { della sostanza bianca } \\
\text { periventricolare; può } \\
\text { essere normale }\end{array}$ & $\begin{array}{l}\text { Ridotta concentra- } \\
\text { zione liquorale di } \\
\text { 5-metiltetraidrofolato }\end{array}$ & Acido folinico \\
\hline $\begin{array}{l}\text { Alterazione dei nuclei } \\
\text { della base che rispon- } \\
\text { de al trattamento con } \\
\text { tiamina e biotina }\end{array}$ & SLC19A3 & Infanzia & $\begin{array}{l}\text { Encefalopatia } \\
\text { acuta ad andamento } \\
\text { ricorrente, distonia, } \\
\text { spasticità, atassia, } \\
\text { crisi epilettiche }\end{array}$ & $\begin{array}{l}\text { Iperintensità nelle } \\
\text { sequenze T2 pesate a } \\
\text { livello dei nuclei della } \\
\text { base e del tronco } \\
\text { encefalico }\end{array}$ & $\begin{array}{l}\text { Elevate concentrazio- } \\
\text { ni liquorali di lattato, } \\
\text { alterazioni del profilo } \\
\text { degli acidi organici } \\
\text { urinari }\end{array}$ & Tiamina, biotina \\
\hline $\begin{array}{l}\text { Deficit di piruvato } \\
\text { deidrogenasi }\end{array}$ & PDHA1, DLAT, altri & Infanzia & $\begin{array}{l}\text { Atassia (può essere } \\
\text { intermittente nelle } \\
\text { forme più lievi), ipoto- } \\
\text { nia, disabilità intellet- } \\
\text { tiva, crisi epilettiche, } \\
\text { discinesia indotta } \\
\text { dall'esercizio (rara) }\end{array}$ & $\begin{array}{l}\text { Ventricolomegalia, } \\
\text { disgenesia del corpo } \\
\text { calloso, iperintensità } \\
\text { nelle sequenze T2 } \\
\text { pesate a livello dei } \\
\text { nuclei della base e } \\
\text { del tronco encefalico }\end{array}$ & $\begin{array}{l}\text { Elevati livelli di latta- } \\
\text { to, piruvato (palsma, } \\
\text { liquor cefalorachi- } \\
\text { diano) con normale } \\
\text { rapporto lattato/ } \\
\text { piruvato }\end{array}$ & $\begin{array}{l}\text { Dieta chetogena, } \\
\text { tiamina }\end{array}$ \\
\hline Deficit di biotinidasi & $B T D$ & Infanzia & $\begin{array}{l}\text { Atassia, ipotonia, } \\
\text { crisi epilettiche, rash } \\
\text { cutanei eczematosi, } \\
\text { alopecia }\end{array}$ & $\begin{array}{l}\text { Atrofia cerebrale con } \\
\text { iperintensità della } \\
\text { sostanza bianca nelle } \\
\text { sequenze T2 pesate }\end{array}$ & $\begin{array}{l}\text { Alte concentrazioni } \\
\text { sieriche di ammonio, } \\
\text { elevati livelli di } \\
\text { lattato, possibili } \\
\text { alterazioni nel profili } \\
\text { degli acidi organici } \\
\text { urinari; ridotta atti- } \\
\text { vità enzimatica della } \\
\text { biotinidasi }\end{array}$ & Biotina \\
\hline Deficit Coenzima 010 & COOBA, PDSS2, altri & $\begin{array}{l}\text { Dall'infanzia all'età } \\
\text { adulta }\end{array}$ & $\begin{array}{l}\text { Atassia, possibile } \\
\text { encefalopatia, spasti- } \\
\text { cità, crisi epilettiche, } \\
\text { miopatia, disabilità } \\
\text { intellettiva, sordità } \\
\text { neurosensoriale }\end{array}$ & $\begin{array}{l}\text { Può essere presente } \\
\text { atrofia cerebellare }\end{array}$ & $\begin{array}{l}\text { Elevati livelli plasma- } \\
\text { tici di lattato, ridotte } \\
\text { concentrazioni di } \\
\text { coenzima } 010\end{array}$ & $\begin{array}{l}\text { Coenzima } 010 \\
\text { (ubichinone) }\end{array}$ \\
\hline $\begin{array}{l}\text { Sindromi da deficit } \\
\text { cerebrale di creatina }\end{array}$ & GAMT, GATM, SLC6A8 & Infanzia, adolescenza & $\begin{array}{l}\text { Distonia, corea, atas- } \\
\text { sia, crisi epilettiche, } \\
\text { disabilità intellettiva, } \\
\text { iperattività, disturbi } \\
\text { del comportamento }\end{array}$ & $\begin{array}{l}\text { Iperintensità nelle } \\
\text { sequenze T2 pesate } \\
\text { a livello del globo } \\
\text { pallido; l'esame RM } \\
\text { encefalo può essere } \\
\text { normale }\end{array}$ & $\begin{array}{l}\text { Elevati livelli di } \\
\text { acido guanidinacetico } \\
\text { (GAA), bassi livelli } \\
\text { di creatina (urine e } \\
\text { plasma) }\end{array}$ & $\begin{array}{l}\text { Limitazione nell'as- } \\
\text { sunzione di arginina, } \\
\text { suplementazione di } \\
\text { creatina e ornitina }\end{array}$ \\
\hline $\begin{array}{l}\text { Atassia con deficit di } \\
\text { vitamina E }\end{array}$ & TाPA & Infanzia, adolescenza & $\begin{array}{l}\text { Atassia, distonia, } \\
\text { tremore del capo; } \\
\text { può essere presente } \\
\text { neuropatia periferica } \\
\text { e riduzione della } \\
\text { sensibilità vibratoria }\end{array}$ & $\begin{array}{l}\text { Può essere presente } \\
\text { atrofia cerebellare } \\
\text { (in circa la metà } \\
\text { dei casi descritti in } \\
\text { letteratura) }\end{array}$ & $\begin{array}{l}\text { Riduzione dei livelli } \\
\text { plasmatici di vitamina } \\
\text { E }\end{array}$ & Vitamina $\mathrm{E}$ \\
\hline Malattia di Wilson & ATP7B & Infanzia, adolescenza & $\begin{array}{l}\text { Distonia, parkinsoni- } \\
\text { smo, tremore, sintomi } \\
\text { da malattia epatica }\end{array}$ & $\begin{array}{l}\text { Alterazioni di } \\
\text { segnale iperintense } \\
\text { nelle sequenze T2 } \\
\text { pesate interessanti } \\
\text { i nuclei della base } \\
\text { e il mesencefalo; } \\
\text { possibile presenza } \\
\text { di iperintensità nelle } \\
\text { sequenze T1 pesate } \\
\text { del globo pallido }\end{array}$ & $\begin{array}{l}\text { Livelli sierici ridotti } \\
\text { o normali di rame e } \\
\text { ceruloplasmina; au- } \\
\text { mento dell'escrezione } \\
\text { urinaria di rame }\end{array}$ & $\begin{array}{l}\text { Agenti chelanti il } \\
\text { rame; zinco; trapianto } \\
\text { epatico per i pazienti } \\
\text { che non rispondono } \\
\text { alla terapia medica } \\
\text { o con insufficienza } \\
\text { epatica acuta }\end{array}$ \\
\hline Ipermanganesemia & SLC30A10 & Infanzia, età adulta & $\begin{array}{l}\text { Distonia, parkinso- } \\
\text { nismo, policitemia, } \\
\text { sintomi da malattia } \\
\text { epatica }\end{array}$ & $\begin{array}{l}\text { Iperintensità nelle } \\
\text { sequenze T1 pesate a } \\
\text { livello dei nuclei della } \\
\text { base con risparmio } \\
\text { dei talami }\end{array}$ & $\begin{array}{l}\text { Elevati livelli ematici } \\
\text { di manganese }\end{array}$ & $\begin{array}{l}\text { Chelazione con calcio } \\
\text { edetato bisodico; } \\
\text { ferro }\end{array}$ \\
\hline
\end{tabular}

* Le mutazioni a carico del gene FOLR1 rappresentano una rara causa di deficit cerebrale di folati; la causa più comune di questa condizione è rappresentata dalla presenza di autoanticorpi che si legano al recettore per i folati. 
ralisi cerebrale infantile forma discinetica è il fenotipo attribuito al $10-15 \%$ dei bambini con paralisi cerebrale infantile i cui sintomi motori sono prevalentemente rappresentati da movimenti involontari; i bambini con paralisi cerebrale infantile forma discinetica possono presentare una combinazione di distonia e atetosi con spesso associata ipotonia assiale con o senza spasticità a livello degli arti; la paralisi cerebrale infantile forma discinetica è tipicamente associata a lesioni a livello dei nuclei della base; la distonia è un disturbo del movimento comune nei bambini con paralisi cerebrale infantile di altro tipo incluse le forme emiplegiche, diplegiche e tetraplegiche che hanno lesioni cerebrali che risparmiano i nuclei della base.

\section{Disturbi del movimento parossistici}

\section{Discinesie parossistiche}

Le discinesie parossistiche sono disturbi del movimento di tipo ipercinetico che clinicamente possono manifestarsi con corea, distonia, atetosi e ballismo, isolati o in combinazione, con episodi circoscritti; le persone che ne sono affette sono asintomatiche tra un episodio e l'altro. Le discinesie parossistiche possono essere indotte dal movimento (PKD), non indotte dal movimento (PNKD) e indotte dall'esercizio (PED). La classificazione di questi disturbi del movimento si basa su caratteristiche cliniche e genetiche (Tabelle 9-10). La diagnosi differenziale di tali disturbi è ampia e include i disturbi del movimento di tipo psicogenetico, le crisi epilettiche e altri disturbi del movimento. Cause secondarie di discinesie parossistiche includono infezioni, cause metaboliche, malformazioni strutturali e malattie neoplastiche (Tabella 11). Il trattamento dipende dal tipo di discinesia (es. le forme PKD rispondono alla terapia antiepilettica mentre le forme PNKD e PED rispondono all'evi- tamento dei fattori trigger e dell'esercizio rispettivamente).

\section{Atassie intermittenti ed episodiche}

Le atassie episodiche sono un gruppo di disturbi del movimento a trasmissione autosomico dominante caratterizzate da attacchi intermittenti di atassia con di solito associate alterazioni neurologiche nei periodi interictali di grado lieve-moderato. L'età d'esordio può variare dai 2 ai 20 anni. I pazienti con atassia episodica tipo 1 (determinata da mutazioni a livello del gene $K C N A 1$ ) tipicamente presentano brevi attacchi di atassia, di durata che può variare da alcuni secondi a minuti, che possono essere scatenati da uno spavento improvviso o dall'esercizio e presentano tra un attacco e l'altro fenomeni di miochimia all'esame neurologico. I pazienti con atassia episodica tipo 2 (la più comune causa di atassia episodica, determinata da mutazioni a livello del gene $C A C N A 1 A$ ) presentano attacchi di atassia che durano da minuti a ore e possono presentare nistagmo indotto dalla fissazione nei periodi interictali. Alcuni pazienti con atassia episodica tipo 2 possono sviluppare nel tempo un'atassia progressiva. $\mathrm{Ci}$ sono anche altre più rare forme di atassia episodica descritte in alcune famiglie. Il trattamento con acetazolamide può essere efficace nel prevenire gli attacchi soprattutto nell'atassia episodica tipo 2 (Jen JC, et al. 2018). Alcune condizioni che si presentano con atassia ricorrente possono essere dovute ad alterazioni metaboliche trattabili; queste patologie possono presentarsi in infanzia o nel periodo preadolescenziale e si caratterizzano per la presenza di atassia intermittente che può essere associata a segni clinici di encefalopatia; alcuni esempi sono rappresentati dalle acidurie organiche (es. metilmalonico aciduria, acidemia propionica), dai difetti del ciclo dell'urea (es. deficit di ornitina transcarbamilasi), forme lievi-mo- derate di deficit di piruvato deidrogenasi e deficit di biotinidasi.

\section{Emiplegia alternante}

L'emiplegia alternante è una patologia neurologica rara che colpisce circa 1 bambino su 1.000.000, con esordio in età infantile, caratterizzata clinicamente da episodi ricorrenti di emiplegia interessanti ad alterna prevalenza entrambi gli emilati del corpo e da altre manifestazioni parossistiche come crisi epilettiche, attacchi distonici, tetraplegia, movimenti oculari anomali e disfunzione autonomica; gli episodi hanno una frequenza variabile, possono durare da pochi minuti a diversi giorni e in genere si risolvono durante il sonno; tale condizione è causata principalmente da mutazioni patogenetiche de novo a livello del gene ATP1A3 (Masoud M, et al. 2017). Sono spesso presenti in comorbidità altri disturbi come per esempio l'epilessia, il disturbo da deficit di attenzione con iperattività (ADHD), problematiche di tipo comportamentale, anomalie nel funzionamento cognitivo/adattivo, difficoltà di apprendimento, atassia, disturbi del movimento, emicrania e alterazioni della conduzione cardiaca. Non esiste a oggi una terapia in grado di modificare il decorso di malattia; alcune strategie terapeutiche prevedono l'utilizzo di benzodiazepine, flunarizina, topiramato, dieta chetogena, trieptanoina, steroidi, amantadina, memantina, aripiprazolo, ATP orale, coenzima $\mathrm{Q}$ acetazolamide, dextrometorfano e stimolazione vagale per il trattamento degli attacchi acuti o per ridurre la frequenza e l'intensità degli episodi ricorrenti (Samanta D. 2020).

\section{Encefalopaie epilettico-discinetiche}

Si tratta un gruppo clinicamente e geneticamente eterogeneo di condizioni che possono manifestarsi in epoca infantile precoce con

\begin{tabular}{|c|c|c|c|}
\hline Caratteristiche & PKD & PNKD & PED \\
\hline Durata & $<1$ minuto & da minuti a ore & da minuti a ore \\
\hline Comuni fattori trigger & movimento improvviso & alcol, caffeina, stress & esercizio \\
\hline Rapporto maschi/femmine & $2: 1$ & $1.5: 1$ & $1: 1$ \\
\hline Frequenza & 100/al giorno & poche volte al giorno & variabile (in genere una volta al giorno) \\
\hline
\end{tabular}

\begin{tabular}{|l|l|l|l|}
\hline \multicolumn{2}{|c|}{ TABEELIA 10. Genetica delle discinesie parossistiche (modificata da Camargo, et al. 2014). } \\
\hline DYTn & Denominazione clinica & \multicolumn{1}{|c|}{ Locus genetico } & \multicolumn{1}{c|}{ Gene } \\
\hline DYT20 & PNKD tipo 1 & $2 q$ & MR-1 \\
\hline DYT10 & PNKD tipo 2 & $2 q$ & - \\
\hline DYT19 & PKD tipo 1 & $16 \mathrm{pq}$ & PRRT2 \\
\hline DYT18 & PKD tipo 2 & $16 q$ & - \\
\hline & PED & $1 \mathrm{p}$ & SLC2A1 \\
\hline
\end{tabular}


sintomi che vanno da un disturbo ipercinetico del movimento (più frequentemente corea, ma anche distonia e stereotipie) fino a gravi forme di encefalopatia epilettica. $\mathrm{Mu}-$ tazioni a livello dei geni FOXG1, GNAO1, GRIN1, SCN8A, FRRS1L, GPR88, UN$C 13 A$ e $S Y T 1$ sono stati descritti come associati a tali patologie (Carecchio M, et al. 2017; Mencacci NE, et al. 2016; De Gusmao CM, et al. 2018) e questa lista è destinata a estendersi in relazione ai continui progressi della genetica molecolare.

\section{Valutazione clinica del bambino con disturbo del movimento}

Nel bambino può essere difficile distinguere i movimenti fisiologici da un disturbo del movimento. La diagnosi di un disturbo del movimento richiede un'osservazione diretta del movimento finalizzata a descriverne la fenomenologia ed è per questo molto utile effettuare o richiedere ai genitori registrazioni video che consentano un'attenta analisi del movimento del bambino.

\section{Valutazione ambulatoriale}

Anamnesi: una valutazione precisa di un bambino con disturbo del movimento inizia da un'accurata raccolta anamnestica particolarmente orientata alla storia del disturbo del movimento del paziente. È importante, quando possibile, ottenere informazioni direttamente dal bambino e integrare tali informazioni con i dati anamnestici forniti dai genitori (Tabella 12). Elementi particolarmente importanti da analizzare includono il possibile effetto di elementi di rischio di danno cerebrale nel periodo perinatale (es. prematurità, parto complicato, altri fattori che hanno reso necessario accesso in terapia intensiva neonatale), l'età d'esordio dei primi sintomi, la storia familiare, le caratteristiche dello sviluppo psicomotorio, il tipo di andamento nel tempo dei sintomi (stabili? progressivi? intermittenti/fluttuanti? peggiorati dallo stress, da malattie intercorrenti o dall'esercizio fisico?).

È altrettanto importante indagare sulla storia della gravidanza, del periodo perinatale, dello sviluppo psicomotorio, analizzare la presenza di eventuali problematiche di tipo psicologico presenti, l'anamnesi familiare, la presenza di problematiche di tipo sociale e di altre possibili patologie mediche presenti. Esame obiettivo generale: oltre che agli aspetti della normale valutazione della visita medica particolare attenzione andrà posta all'identificazione di possibili dismorfismi indicativi di una specifica condizione sindromica, alla ricerca di alterazioni cutanee suggestive di una sindrome neurocutanea e alla palpazione degli organi addominali alla ricerca di organomegalie presenti in alcune malattie da accumulo; il riscontro di alcune specifiche

\begin{tabular}{|l|l|}
\hline TABELLA 11. Discinesie parossistiche secondarie. \\
\hline $\begin{array}{l}\text { Infezioni del sistema } \\
\text { nervoso centrale }\end{array}$ & CMV, sifilide, AIDS, panencefalite sclerosante subacuta \\
\hline $\begin{array}{l}\text { Malattie/alterazioni } \\
\text { metaboliche }\end{array}$ & $\begin{array}{l}\text { Malattia di Wilson, malattia delle urine a sciroppo d'acero, pseudopa- } \\
\text { raipotiroidismo con calcificazioni dei nuclei della base, ipoparatiroidi- } \\
\text { smo, tireotossicosi, ipoglicemia/insulinoma, iperglicemia, ipocalcemia, } \\
\text { diabete }\end{array}$ \\
\hline Traumi & $\begin{array}{l}\text { Danno anossico cerebrale, lesioni del midollo spinale, paralisi cerebra- } \\
\text { le, trauma cranico }\end{array}$ \\
\hline Patologie vascolari & Malattia di Moyamoya, attacco ischemico transitorio, stroke \\
\hline Patologie tumorali & Mengioma parasagittale, linfoma del sistema nervoso centrale \\
\hline Malformazioni strutturali & Malformazione di Arnold-Chiari con siringomielia, displasia corticale \\
\hline Indotte da farmaci & Terapia con metilfenidato \\
\hline Altre cause & Paralisi sopranucleare progressiva, neuroacantocitosi \\
\hline
\end{tabular}

\section{TABELLA 12. Informazioni anamnestiche mirate ad analizzare la storia} del disturbo del movimento.

\section{- Il bambino è consapevole del disturbo del movimento presente?}

- Chi nota di più o chi è più preoccupato e/o stressato dalla presenza del disturbo del movimento?

- II disturbo del movimento viene percepito dal bambino come volontario ("Io sto facendo"), involontario ("accade") 0 entrambi?

- Che tipo di esordio ha avuto e qual è l'andamento del disturbo del movimento?

- Esistono dei fattori o delle situazioni che sembrano accentuare o attenuare il disturbo del movimento?

- Il disturbo del movimento si accentua o si riduce in alcuni momenti della giornata?

- II disturbo del movimento è presente 0 assente durante il sonno?

- Il disturbo del movimento si associa a sensazioni di tipo premonitorio o a sensazione di dover mettere in atto con urgenza il movimento?

- I movimenti sono sopprimibili con la volontà o con stratagemmi di tipo sensoriale?

- Ci sono dei segni o sintomi di tipo neurologico o non neurologico in associazione?

- II disturbo del movimento causa dolore? Interferisce con lo svolgimento delle normali attività di vita quotidiana? Causa imbarazzo al bambino?

- II bambino è già stato sottoposto a precedenti valutazioni/esami?

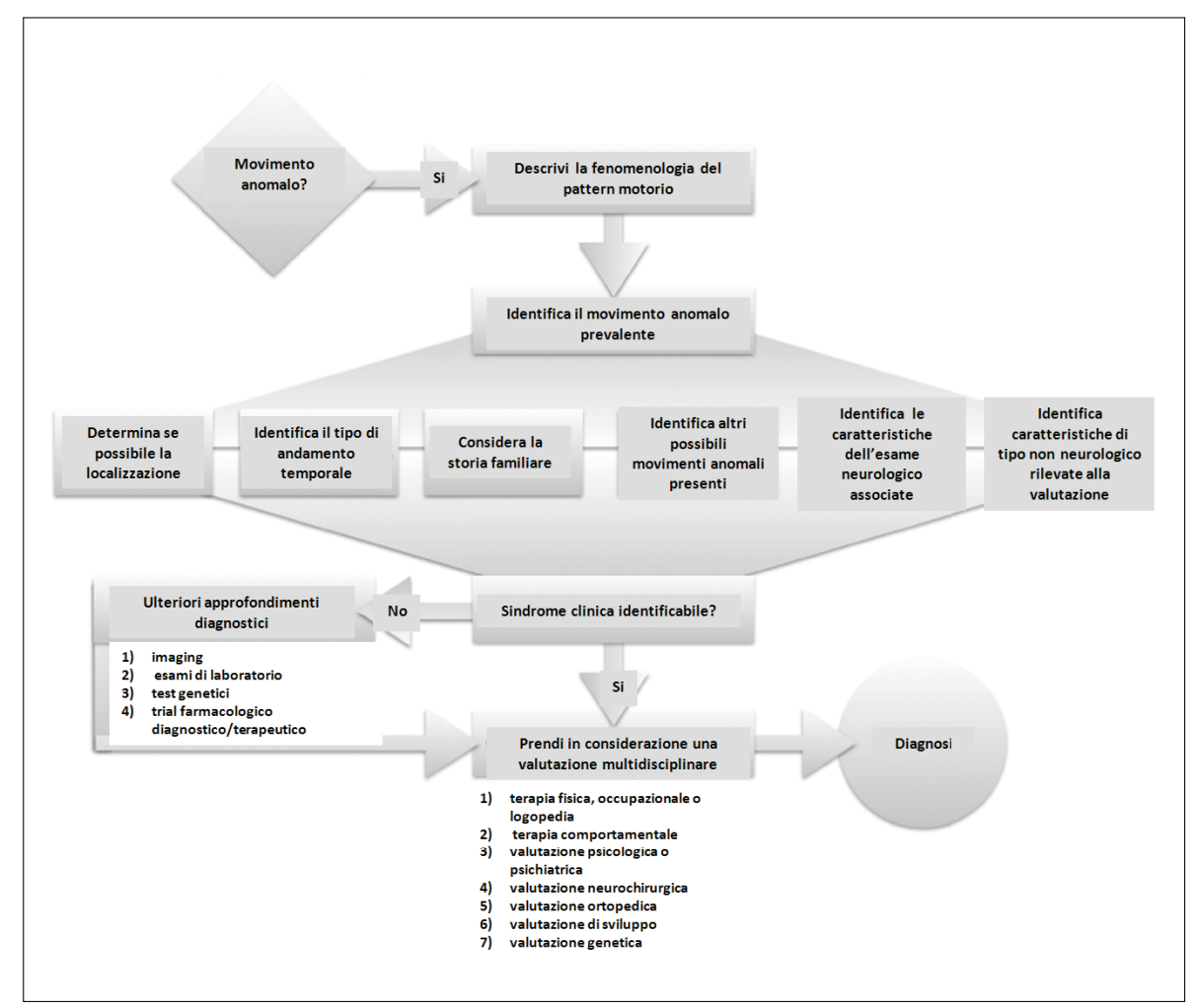

Figura 4. Approccio diagnostico al bambino con disturbo del movimento (modificata da O'Malley JA, et al. 2017). 
alterazioni a livello oculare può fornire elementi che orientano fortemente la diagnosi verso specifiche condizioni patologiche (es. anelli di Kayser-Fleischer suggestivi di malattia di Wilson, retinopatia pigmentaria $o$ atrofia ottica entrambe associate a forme neurodegenerativa con accumulo intracerebrale di ferro); una valutazione muscoloscheletrica sarà fondamentale per valutare l'eventuale presenza di anomalie strutturali interessanti tronco e arti.

Esame neurologico: la valutazione neurologica del bambino con disturbo del movimento deve avvalersi di tecniche che tengano conto dell'età del paziente e che possano essere utili per accentuare o ridurre i movimenti anomali presenti (es. gioco, distrazione). È molto utile inoltre filmare la valutazione neurologica sia per analizzare nel dettaglio le caratteristiche del disturbo del movimento che per monitorarne l'evoluzione clinica nel tempo e anche per poter discutere il caso con un team multidisciplinare o di esperti in disturbi del movimento. In epoca infantile molto precoce risulta particolarmente importante la valutazione dei "General movements (GMs)", tecnica sviluppata dal professor Heinz Prechtl e collaboratori, che consiste nell'osservazione/ analisi del repertorio dei movimenti spontanei presenti nel bambino dalla nona/decima settimana di vita fetale fino al quinto/ sesto mese di età post termine (Einspieler C, et al. 2005); l'analisi dei GMs è stata dimostrata essere una tecnica molto sensibile e specifica oltre che non invasiva ed economica per la diagnosi precoce di paralisi cerebrale infantile.

\section{Raggiungimento della diagnosi}

L'approccio fenomenologico richiede delle abilità nel riconoscimento dei disturbi del movimento che si basa su competenze specialistiche rinforzate dall'esperienza clinica. Losservazione del disturbo del movimento in aggiunta ai dati anamnestici e a quelli derivanti dalla valutazione del $\mathrm{pa}^{-}$ ziente consentono nella maggioranza dei casi di raggiungere una precisa diagnosi o almeno di localizzare la sede anatomica origine del disturbo del movimento. L'esame neuroradiologico con RM encefalo è generalmente indicato nelle fasi iniziali del percorso diagnostico e consente di rilevare eventuali lesioni strutturali o specifiche lesioni o alterazioni di segnale che possano fortemente orientare la diagnosi o restringere l'ambito delle possibili diagno-

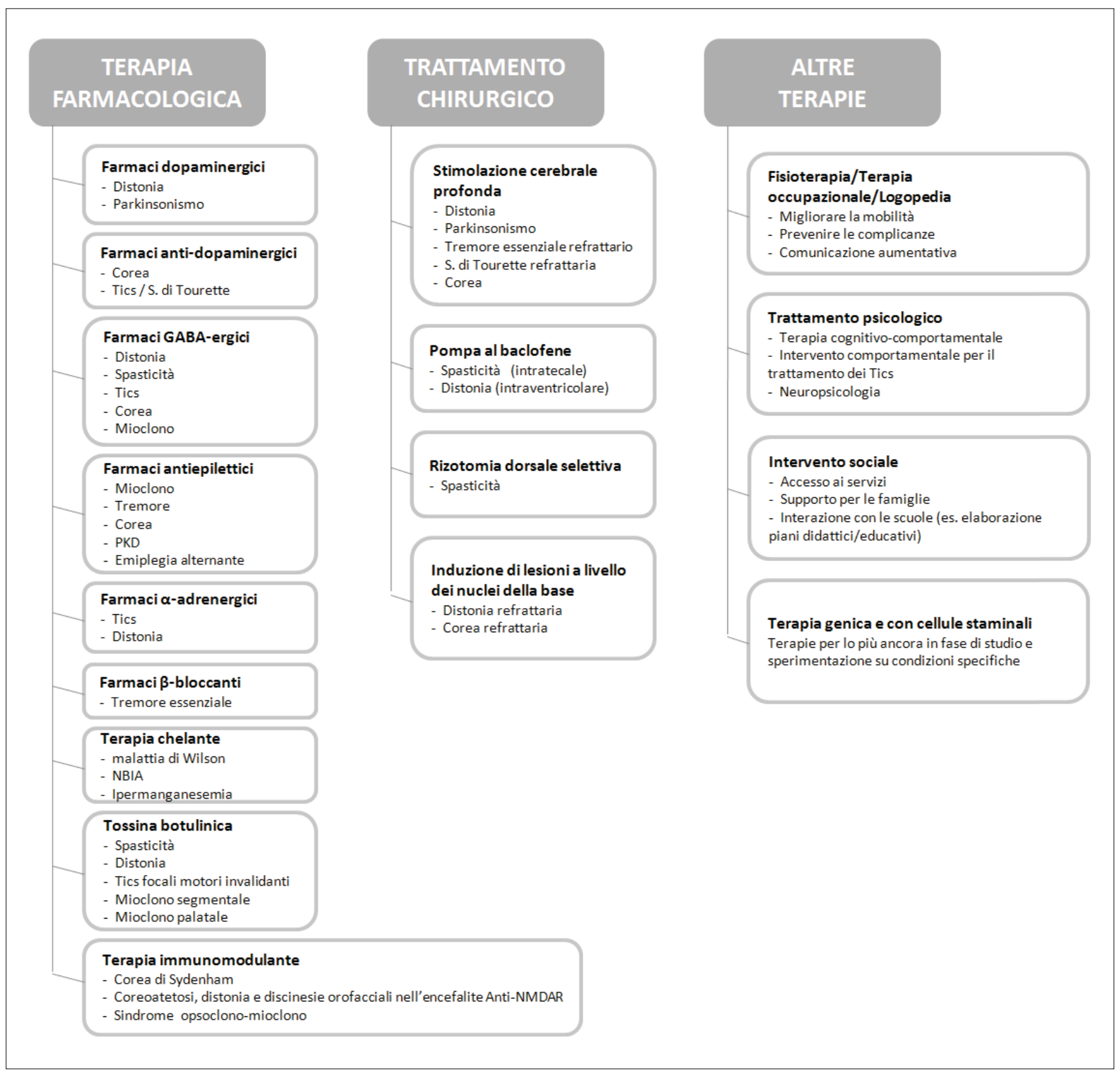

Figura 5. Possibili opzioni terapeutiche nei disturbi del movimento. 
si differenziali. La diagnosi differenziale può essere via via ristretta mettendo insieme la storia clinica, il tipo di andamento del disturbo del movimento nel tempo, l'età del paziente all'esordio dei sintomi e le caratteristiche dell'esame neuroradiologico. Nel caso in cui la fenomenologia del disturbo del movimento e la storia clinica non siano sufficienti a raggiungere una diagnosi è fondamentale escludere cause secondarie (es. esposizione, ingestione o sospensione di farmaci o sostanze tossiche, infezioni, processi infiammatori, cause vascolari o traumatiche, malattie metaboliche o altre condizioni geneticamente determinate) (Figura 4).

\section{Trattamento}

Il trattamento dei disturbi del movimento comprende una vasta gamma di opzioni che spaziano dalla terapia farmacologica agli interventi di neuromodulazione invasiva fino a tecniche sperimentali che prevedono l'utilizzo della terapia genica e delle cellule staminali (Russ JB, et al. 2018) (Figura 5). L'efficacia clinica di queste terapie è variabile è spesso poco supportata da studi controllati randomizzati con coorti selezionate in base a età e a caratteristiche cliniche specifiche (Koy A, et al. 2016). Le attuali conoscenze e applicazioni sul trattamento dei disturbi del movimento in età pediatrica, a parte poche eccezioni, sono per lo più ricavate da risultati di studi randomizzati effettuati su pazienti adulti con problematiche simili. I principali obiettivi del trattamento dei disturbi del movimento sono migliorare o limitare l'effetto negativo dei movimenti anomali, ridurre il dolore se presente e migliorare la qualità della vita del paziente. La maggior parte dei trattamenti farmacologici e non farmacologici dei disturbi del movimento in età pediatrica risultano in Italia così come in molti altri Paesi off-label. È auspicabile che in un futuro non lontano sia possibile acquisire dati derivanti da studi specifici su popolazioni pediatriche selezionate al fine di accrescere le conoscenze su tollerabilità, sicurezza ed efficacia dei trattamenti disponibili e valutare la possibilità di applicare eventuali nuove terapie.

\section{Conclusion}

I disturbi del movimento in età pediatrica rappresentano un grosso gruppo di condizioni geneticamente determinate o acquisite. L'analisi della fenomenologia motoria, la caratterizzazione del disturbo del movimento, il decorso clinico, la progressione temporale dei sintomi neurologici nel contesto dello sviluppo del bambino e l'eventuale presenza di altri sintomi associati rappresentano elementi chiave per il raggiungimento di una corretta diagnosi. Trattamenti che modificano in maniera significativa il decorso di malattia sono disponibili per molti disturbi del movimento a esordio acuto e per alcune specifiche condizioni ad andamento cronico. Negli ultimi anni l'avanzamento tecnologico nella diagnostica molecolare ha consentito l'identificazione delle cause genetiche e dei meccanismi eziologici alla base di molti disturbi del movimento e la caratterizzazione di nuove condizioni; questi rapidi progressi in ambito diagnostico non sono stati seguiti da altrettanto significativi miglioramenti in ambito terapeutico che risultano comunque a oggi in continua evoluzione.

\section{giovanni.tricomi@ausIromagna.it}

Albanese A, Bhatia K, Bressman SB, et al. Phenomenology and classification of dystonia: a consensus update. Mov Disord. 2013 Jun 15;28(7):863-73.

Bonnet C, Roubertie A, Doummar D, et al. Developmental and benign movement disorders in childhood. Mov Disord. 2010 Jul 30;25(10):1317-34.

Camargo CHF, Camargos ST, Cardoso FEC, Teive HAG. The genetics of the dystonias a review based on the new classification of the dystonias. Arq Neuropsiquiatr. 2015 Apr;73(4):350-8.

Carecchio M, Mencacci NE. Emerging Monogenic Complex Hyperkinetic Disorders. Curr Neurol Neurosci Rep. 2017 Oct 30;17(12):97.

De Gusmao CM, Waugh JL. Inherited and Acquired Choreas. Semin Pediatr Neurol. 2018 Apr;25:42-53.

Einspieler C, Prechtl HFR. Prechtl's assessment of general movements: a diagnostic tool for the functional assessment of the young nervous system. Ment Retard Dev Disabil Res Rev. 2005;11(1):61-7.
Fernández-AlvarezE. Transient benign paroxysmal movement disorders in infancy. Eur J Paediatr Neurol. 2018 Mar;22(2):230-7.

Hao SS, Feng YH, Zhang GB, et al. Neuropathophysiology of paroxysmal, systemic, and other related movement disorders. Eur Rev Med Pharmacol Sci. 2015 Jul;19(13):2452-60.

Jankovic J, Lang AE. Diagnosis and Assessment of Parkinson's Disease and Other Movement disorders. In Daroff RB, Jankovic J, Maziotta J, Pomeroy S (a cura di). Bradley's Neurology in Clinical Practice. Butterworth-Heinemann (Elsevier), 2016 :223.

Jen JC, Wan J. Episodic ataxias. Handb Clin Neurol. 2018;155:205-15.

Koy A, Lin JP, Sanger TD, et al. Advances in management of movement disorders in children. Lancet Neurol. 2016 Jun;15(7):719-35.

Marsden CD, Hallett M, Fahn S. The nosology and pathophysiology of myoclonus. In: Marsden CD, Fahn S (a cura di). Movement disorders. Butterworths, 1983:196-248.

Masoud M, Prange L, Wuchich J, et al. Diagnosis and Treatment of Alternating Hemiplegia of Childhood. Curr Treat Options Neurol. $2017 \mathrm{Feb} ; 19(2): 8$.

Mencacci NE, Carecchio M. Recent advances in genetics of chorea. Curr Opin Neurol. 2016 Aug;29(4):486-95.

Méneret A, Roze E: Paroxysmal movement disorders: An update. Rev Neurol (Paris). AugSep 2016;172(8-9):433-45.

O’Malley JA, Gilbert DL. Clinical Approach to a Child with Movement Disorders.SeminPediatr Neurol 2018;25:10-8. doi: 10.1016/j. spen.2017.12.001. Epub2017 Dec 20. Review.

Russ JB, Nallappan AM, Robichaux-Viehoever A. Management of Pediatric Movement Disorders: Present and Future. Semin Pediatr Neurol. 2018 Apr;25:136-51.

Ruzbarsky JJ, Scher D, Dodwell E. Toe walking: causes, epidemiology, assessment, and treatment. Curr Opin Pediatr. 2016 Feb;28(1):40-6.

Samanta D. Management of Alternating Hemiplegia of Childhood: A Review. Pediatr Neurol. 2020 Feb;103:12-20.

Sanger TD, Chen D, Fehlings DL, et al. Definition and classification of hyperkinetic movements in childhood. Mov Disord. 2010 Aug 15;25(11):1538-49.

Sanger TD, Delgado MR, Gaebler-Spira D, et al. Classification and definition of disorders causing hypertonia in childhood. Pediatrics. 2003 Jan;111(1):e89-97.

Sanger TD. Pediatric movement disorders. Curr Opin Neurol. 2003 Aug;16(4):529-35.

Singer H, Mink J, Gilbert D, et al. Paroxysmal Dyskinesias, Movement Disorders in Childhood. Elsevier Inc, 2016:127-39. 